\title{
Medium optimization for exopolysaccharides production by Bacillus Zhangzhouensis BZ 16 strain isolated from Khnifiss Lagoon
}

\author{
Mouna Miri ${ }^{1, *}$, Hafida Bergayou ${ }^{1}$, Ahmed Belmouden ${ }^{1}$, Abdellatif Moukrim ${ }^{2}$, Hakim Baazizi $^{3}$, and Naima Boum'handi ${ }^{3}$ \\ ${ }^{1}$ University Ibn Zohr, Faculty of sciences, Department of Biology, Laboratory of AQUAMAR, Agadir, Morocco. \\ ${ }^{2}$ University Abdelamalek Essadi, Faculty of Sciences, Tetouan, Morocco. \\ ${ }^{3}$ The Specialized Center of Valorization and Technology of Marine Products (CSVTPM), National Marine Research Institute (INRH), \\ Laboratory quality control, Agadir, Morocco.
}

\begin{abstract}
The increased demand for natural polymers for diverse industrial applications in last years has led to a renovated interest in exopolysaccharides (EPS) production by microorganisms. Ecological roles of EPS especially for those isolated from extreme habitats such as hypersaline ponds have been reported in several studies. A moderate halophilic strain producing exopolysaccharide (EPS) has been isolated earlier. However, the EPS production of the strain $(2 \mathrm{~g} / \mathrm{L})$ was relatively low to exploit it at the industrial level. In the present work, the strain was identified as Bacillus zhangzhouensis and named as BZ 16 and the optimal medium was studied to boost the EPS production. Maximum EPS production was obtained in medium with $125 \mathrm{~g} / \mathrm{L}$ sucrose, $30 \mathrm{~g} / \mathrm{L}$ yeast extract. Phosphate source inhibited EPS production even if it increased the growth. Under optimal medium composition, EPS was produced at $12.37 \mathrm{~g} / \mathrm{L}$, which was 6 times greater than the production yield achievable without optimizing conditions.
\end{abstract}

\section{Introduction}

Moderately halophilic bacteria are widely present in the hypersaline environment and have been recognized as precious sources of novel biomolecules including exopolysaccharides [1]. These exopolysaccharides (EPS) are thought to play important role in protecting against desiccation, toxic compounds, bacteriophages, osmotic stress, at the same time as allowing attachment with substrates, adhesion to solid surfaces and facilitating the development of biofilms [2]. EPS contribute also in the conservation of enzymes, defence against attack and protection against variation in physicochemical conditions [3].

EPS have stirred great interest among biotechnologists because of their physico-chemical characteristics allowing their commercial application in wide range of fields such as medicine, pharmacy, food, cosmetics and the petroleum industry [2,4-6]. In addition to their contribution in the biogeochemical cycling in the ocean [7], today, polysaccharides represent a possible ecological substitute of petroleum industry, as their sources are renewable and not pollutant. Furthermore, they are biodegradable, not toxic and their chemical degradation can produce biofuel with other molecules, which are able to form industrial polymers and fine chemicals [8].

The harnessing of microbial exopolysaccharides is relatively undiscovered and there is a rising research interest in the isolation, characterization and applications of novel exopolysaccharides as renewable resources [9].

EPSs are thought to play a role in protection against desiccation, osmotic stress and attack by bacteriophages or toxic compounds in the environment and helping to form biofilms to afford adherence to solid surfaces (Sutherland 2001). They have aroused great interest among biotechnologists because of their wide range of potential applications in fields such as medicine, pharmacy, foodstuff and cosmetics.

This study aimed at exploring and identifying microorganisms of biotechnological potential in hypersaline environments. These habitats are characterized by their high salinity, low oxygen content and intense solar radiation and often refuge micro-organisms of important biotechnological interest.

Production of EPS by bacterial species in culture is considerably influenced by diverse factors in particular the nature and concentration of nutrients which are indispensable components for stimulation of growth and synthesis of EPS [10].

In a previous study, we isolated moderate halophilic bacteria from salt marshes of Khnifiss lagoon, the EPS production yield of the strain $(2 \mathrm{~g} / \mathrm{L})$ was low to be exploited at the industrial level where at least a $10-15 \mathrm{~g} / \mathrm{L}$ production yield is needed [11]. Thus, the improvement of EPS production is achieved by optimizing the medium composition.

\footnotetext{
*Corresponding author: eng.mouna.miri@gmail.com
} 


\section{Materials \& Methods}

\subsection{Isolation and Identification of Bacterial Strain}

Bacterium strain used in the present study was isolated from salt marshes of Khnifiss lagoon in our laboratory and identified as Bacillus zhangzhouensis. Bacterial DNA was extracted from pure cultures using the Invitrogen extraction kits (Thermo Fisher Scientific laboratory) following the protocol detailed in the kit datasheet. For molecular detection, the primers FD1 (AGAGTTTGATCCTGGCTCAG) and rP2 (ACGGCTACCTTGTTACGACTT) primers [12] synthesized by Bio Basic Inc Canada, which amplify the $16 \mathrm{~S}$ rRNA gene, were used with the described protocol [13]. PCR products were purified with the Gel \& PCR Clean-up of Nucleo Spin ${ }^{\circledR}$ kit, and submitted to the sequencing provider service (CNRST, Morocco) for Sanger sequencing. sequences obtained were examined by BLAST (Basic Local Alignment Search Tool) [14] for calculating sequence similarities. Phylogenetic analyses were done by MEGA7 [15] for homology study. bioinformatics analysis of the sequences allows to identify the BZ 16 as Bacillus zhangzhouensis.

\subsection{Culture conditions}

The strain was grown in MY liquid medium having the following composition (g 1-1): Yeast extract (10); Protease peptone (5); Glucose (1); $\mathrm{NaCl}$ (100); $\mathrm{MgCl} 2+$ $6 \mathrm{H} 2 \mathrm{O}$ (7); $\mathrm{MgSO} 4+7 \mathrm{H} 2 \mathrm{O}$ (9.6); $\mathrm{CaCl} 2+2 \mathrm{H} 2 \mathrm{O}$ (0.36); $\mathrm{KCl}$ (2); NaHCO3 (0.06); NaBr (0.026); agar, (14); pH 7.2. The inoculated media were incubated at $37^{\circ} \mathrm{C}$ for 24 hours on a rotary shaker incubator at $120 \mathrm{rpm}$ and was maintained in a deep freezer $\left(-80^{\circ} \mathrm{C}\right)$ in the same medium supplied with $15 \%(\mathrm{v} / \mathrm{v})$ of glycerol. The frozen stock culture was used to inoculate an $\mathrm{MH}$ agar plate and then transferred to MY as a basal medium containing. The culture was incubated at $120 \mathrm{rpm}$ and $37^{\circ} \mathrm{C}$ for $48 \mathrm{~h}$.

\subsection{Optimisation of conditions for EPS production}

Various changes of the medium were performed to enhance EPS production of the B.zhangzhouensis BZ 16 strain. First, the effect of carbon source supplied in the basal medium was examined by changing glucose to sucrose, fructose, galactose, maltose, mannitol, rhamnose, xylose, or lactose $(50 \mathrm{~g} / \mathrm{L}, \mathrm{w} / \mathrm{v})$. Secondary, the effect of nitrogen source was studied in the optimum carbon source by varying the yeast extract and proteose peptone to ammonium citrate, ammonium nitrate, ammonium oxalate, ammonium sulfate, meat extract, peptone, tryptone, sodium nitrate, and yeast extract (15 g/L, w/v). Dipotassium phosphate, potassium phosphate, disodium phosphate, and sodium phosphate $(5 \mathrm{~g} / \mathrm{L}, \mathrm{w} / \mathrm{v})$ were added to identify the effects of phosphate sources. Cultivation with each different medium preparation was performed after aseptically inoculating plates with $5 \%(\mathrm{v} / \mathrm{v})$ of the overnight seed culture followed by a $48 \mathrm{~h}$ incubation at $120 \mathrm{rpm}$ and $37^{\circ} \mathrm{C}$. Then, the most profitable carbon source for EPS production was varied from 0 to $125 \mathrm{~g} / \mathrm{L}$ to determine the optimal concentration. Similarly, the effects of nitrogen and phosphate sources varying from 0 to $30 \mathrm{~g} / \mathrm{L}$ were investigated and compared.

\subsection{EPS extraction and quantification}

EPS extraction was done according to Kilıç \& Dönmez [16]. $10 \mathrm{~mL}$ of the sample was boiled for $15 \mathrm{~min}$. Then, $4 \%(\mathrm{w} / \mathrm{v})$ TCA was added and subsequently vortexed and centrifuged at $11,200 \mathrm{~g}, 4{ }^{\circ} \mathrm{C}$ for $30 \mathrm{~min}$ to precipitate proteins. The supernatant was transferred into another tube and the same volume of absolute cold ethanol was added. The mixture was stored at $4{ }^{\circ} \mathrm{C}$ overnight. Then it was centrifuged at $11,200 \mathrm{~g}, 4^{\circ} \mathrm{C}$ for $30 \mathrm{~min}$ to precipitate the EPS. The supernatant was removed and pellets containing the EPSs were dissolved in $1 \mathrm{~mL}$ of ultrapure water. The EPS solution was dialyzed with a dialysis bag (MWCO $14 \mathrm{kD}$ ) at $4^{\circ} \mathrm{C}$ for 2 days to eliminate the small impurities.

\subsection{Chemical measurements}

Total sugars were determined using the phenol-sulfuric acid method described by Dubois et al. [17] using a glucose standard curve.

\subsection{Statistics analysis}

Data were analyzed by one-way analysis of variance (ANOVA) using SPSS version 12.0 software (SPSS, Inc., Chicago, IL, USA). All analyses were performed in triplicate, and results are expressed as mean \pm standard deviations (SD). Differences among groups were assessed using Duncan's multiple range test. A $p<0.05$ was considered significant.

\section{Results and Discussion}

\subsection{Effects of carbon source and concentration on EPS production}

It is proved that the yields and compositions of the EPS are impacted by culturing conditions, especially when using various carbon sources $[18,19]$ which yield the necessary energy for cell growth and components for EPS production $[20,21]$. The type of carbon source influences the yield of exopolysaccharide [22].

The effect of carbon sources on EPS production were determined using glucose, fructose, galactose, maltose, mannitol, rhamnose, xylose, lactose and sucrose. As shown in Table 1, B. zhangzhouensis ZB 16 produced significantly more EPS with sucrose $(7.95 \mathrm{~g} / \mathrm{L})$ and mannitol $(6.53 \mathrm{~g} / \mathrm{L})$ than that with the other carbon sources. The specific EPS production rate per biomass $(\mathrm{w} / \mathrm{w})$ was also the highest $(\mathrm{p}<0.05)$ when sucrose and mannitol were used as the sole carbon source (1.22 and $1.17 \mathrm{~g} / \mathrm{g}$ respectively) compared to that of the other carbon sources. EPS was lowest when lactose was used (1.82 $\mathrm{g} / \mathrm{L})$ but the lowest specific EPS production rate was 
obtained with glucose $(0.46 \mathrm{~g} / \mathrm{g})$. The maximum EPS production and increased B.zhangzhouensis BZ 16 cell biomass, when sucrose was used as the sole carbon source, was in good agreement with previous findings, suggesting that sucrose is the most profitable carbon source for EPS mass production [20,23].Also Mannitol occurs in a wide range of living organisms, where it fulfills different physiological roles. In particular, mannitol is likely to be an important source of carbon for marine heterotrophic bacteria [24]. The optimal sucrose concentration was also evaluated in medium containing diverse sucrose concentrations of 0 to $125 \mathrm{~g} / \mathrm{L}$ (Fig. 1A). The highest EPS production yield of $9.12 \mathrm{~g} / \mathrm{L}$ was obtained when the strain was grown in medium containing $75 \mathrm{~g} / \mathrm{L}$ sucrose. Although no significant difference was observed for EPS production yield between 75 and 125 $\mathrm{g} / \mathrm{L}$ substrate concentration $(\mathrm{p}<0.001)$. The specific EPS production rate decreased in $100 \mathrm{~g} / \mathrm{L}$ sucrose concentration due to increased cell mass. Remarkably, microbial growth was not significantly influenced in the concentration range, although EPS production increased by increasing sucrose concentration. The microorganisms can use different carbohydrates and amino acids as carbon source for EPS production, however glucose and sucrose are the most efficient [25].

Table 1. Effects of carbon sources on cell biomass, exopolysaccharide (EPS) production and specific production rates of $B$. zhangzhouensis ZB 16

Biomass $(\mathrm{g} / \mathrm{L}) \quad$ EPS $(\mathrm{g} / \mathrm{L}) \quad$ Specific rate of EPS $($ EPS/biomass, $\mathrm{g} / \mathrm{g})$

\begin{tabular}{l|l} 
Carbon source & \\
Glucose & $4.63 \pm 0.16$ \\
Fructose & $4.03 \pm 0.09$ \\
Galactose & $3.25 \pm 0.08$ \\
Maltose & $4.52 \pm 0.07$ \\
Mannitol & $5.58 \pm 0.20$ \\
Rhamnose & $2.72 \pm 0.10$ \\
Xylose & $3.44 \pm 0.18$ \\
Lactose & $2.76 \pm 0.29$ \\
Sucrose & $6.53 \pm 0.22$
\end{tabular}

\subsection{Effects of nitrogen source and concentration on EPS Production}

The effects of nitrogen sources and their concentrations on cell growth and EPS production by B. zhangzhouensis ZB 16 were examined. As shown in Table 2, the strain produced the highest EPS levels with yeast extract $(11.22 \mathrm{~g} / \mathrm{L})$. The strain offered the lowest EPS yield $(0.52 \mathrm{~g} / \mathrm{L})$ with ammonium oxalate. Moreover, yeast extract used as the sole nitrogen source resulted in a higher yield than that with yeast extract with proteose peptone used in the basal medium. The strain also showed the highest cell growth and EPS production with yeast extract as the sole nitrogen source. We noticed that the biomass was greater when grown in the presence of organic rather than inorganic nitrogen sources. The highest

$2.15 \pm 0.13$
$2.23 \pm 0.2$
$2.52 \pm 0.31$
$3.15 \pm 0.05$
$6.53 \pm 0.15$
$2.21 \pm 0.12$
$2.46 \pm 0.22$
$1.81 \pm 0.07$
$7.95 \pm 0.11$

$0.46 \pm 0.14$

$0.55 \pm 0.15$

$0.78 \pm 0.20$

$0.70 \pm 0.06$

$1.17 \pm 0.17$

$0.82 \pm 0.11$

$0.71 \pm 0.20$

$0.66 \pm 0.18$

$1.22 \pm 0.16$

productivity of EPS was obtained when yeast extract was used in the media followed by malt extract, meat extract, peptone, nutrient broth and tryptone. No differences were found between inorganic nitrogen sources. Thus, yeast extract was ultimately selected as the optimal nitrogen source for mass EPS production and its optimal concentration was determined (Fig. 1B). The highest EPS production yield of $12.37 \mathrm{~g} / \mathrm{L}$ was observed in medium containing $25 \mathrm{~g} / \mathrm{L}$ yeast extract $(p<0.001)$, whereas the highest biomass yield of 8.72 $\mathrm{g} / \mathrm{L}$ was obtained when $B$. zhangzhouensis ZB 16 was grown in medium containing $20 \mathrm{~g} / \mathrm{L}$ ammonium sulfate $(p<0.001)$. Several authors suggest yeast extract is a good substrate for many microorganisms [26,27] because it contains amino acids and peptides, water soluble vitamins and carbohydrates [28]. Also, polysaccharide production is favored by a high carbon/nitrogen ratio, as it is with other EPS-producing microorganisms [29].

Table 2. Effects of nitrogen sources on cell biomass, exopolysaccharide (EPS) production, and specific production rates of $B$. zhangzhouensis ZB 16

Biomass $(\mathrm{g} / \mathrm{L}) \quad$ EPS $(\mathrm{g} / \mathrm{L}) \quad$ Specific rate of EPS

\begin{tabular}{l|ccc}
\hline Nitrogen source & & & (EPS/biomass, $/ \mathrm{g}$ \\
yeast extract & $8.26 \pm 0.18$ & $11.22 \pm 0.15$ & $1.36 \pm 0.21$ \\
meat extract & $7.01 \pm 0.10$ & $9.40 \pm 0.14$ & $1.34 \pm 0.22$ \\
malt extract & $7.92 \pm 0.10$ & $10.52 \pm 0.37$ & $1.33 \pm 0.30$ \\
peptone & $7.26 \pm 0.08$ & $9.21 \pm 0.06$ & $1.27 \pm 0.09$ \\
tryptone & $6.29 \pm 0.24$ & $8.66 \pm 0.17$ & $1.38 \pm 0.26$ \\
nutrient broth & $7.42 \pm 0.12$ & $8.73 \pm 0.14$ & $1.18 \pm 0.17$ \\
ammonium citrate & $4.31 \pm 0.22$ & $2.71 \pm 0.26$ & $0.63 \pm 0.30$ \\
ammonium nitrate & $2.89 \pm 0.35$ & $1.67 \pm 0.08$ & $0.58 \pm 0.27$ \\
ammonium oxalate & $2.40 \pm 0.25$ & $1.24 \pm 0.13$ & $0.52 \pm 0.25$ \\
ammonium sulfate & $4.66 \pm 0.23$ & $6.80 \pm 0.2$ & $1.46 \pm 0.16$ \\
sodium nitrate & $2.18 \pm 0.21$ & $1.23 \pm 0.16$ & $0.56 \pm 0.25$ \\
ammonium chloride & $5.30 \pm 0.19$ & $4.89 \pm 0.25$ & $0.92 \pm 0.31$
\end{tabular}




\subsection{Effects of phosphate source and concentration on EPS production}

The effects of phosphate source on EPS production were examined with dipotassium, potassium, disodium, and sodium phosphates, as the phosphate source has been recognized as an important factor for microbial EPS production $[20,30]$. Among the examined phosphate sources, B. zhangzhouensis $\mathrm{ZB} 16$ produced the greatest amount of EPS with dipotassium phosphate $(10.26 \mathrm{~g} / \mathrm{L})$, whereas the significantly lowest EPS production $(7.16 \mathrm{~g} / \mathrm{L})$ was observed using disodium phosphate, and the highest biomass was obtained when potassium phosphate was used $(9.36 \mathrm{~g} / \mathrm{L})$ (Table 3). However, the highest EPS production yield of $12.33 \mathrm{~g} / \mathrm{L}$ was obtained when B. zhangzhouensis ZB 16 was grown in medium in the absence of dipotassium phosphate $(p<0.001)$ (Fig. 1C). Cell growth didn't increase significantly by the increasing of the dipotassium phosphate concentration from 0 to $30 \mathrm{~g} / \mathrm{L}$. However, unpredictably, all phosphates used in this study inhibited EPS production even though biomass yield increased with increasing concentrations of dipotassium phosphate. It has been mentioned that EPS production is stimulated by limiting phosphate due to environmental stress, indicating that a significant increase in EPS production is related to enhanced expression of EPS synthetic enzymes at the gene level [31].

Table 3. Effects of inorganic phosphate sources on cell biomass, exopolysaccharide (EPS) production and specific production rates of B. zhangzhouensis ZB 16

\begin{tabular}{l|ccr}
\multicolumn{2}{c}{ Biomass $(\mathrm{g} / \mathrm{L})$} & EPS $(\mathrm{g} / \mathrm{L})$ & $\begin{array}{c}\text { Specific rate of } \\
\text { (EPS/biomass, }\end{array}$ \\
\hline Phosphates & & & $3.84 \pm 1.09$ \\
Dipotassium & $2.67 \pm 0.42$ & $10.26 \pm 1.28$ & $1.07 \pm 0.14$ \\
Potassium & $9.36 \pm 0.56$ & $10.04 \pm 0.45$ & $1.56 \pm 0.30$ \\
Disodium & $4.58 \pm 0.36$ & $7.16 \pm 0.35$ & $4.91 \pm 0.94$ \\
Sodium & $1.78 \pm 0.12$ & $8.75 \pm 0.67$ &
\end{tabular}

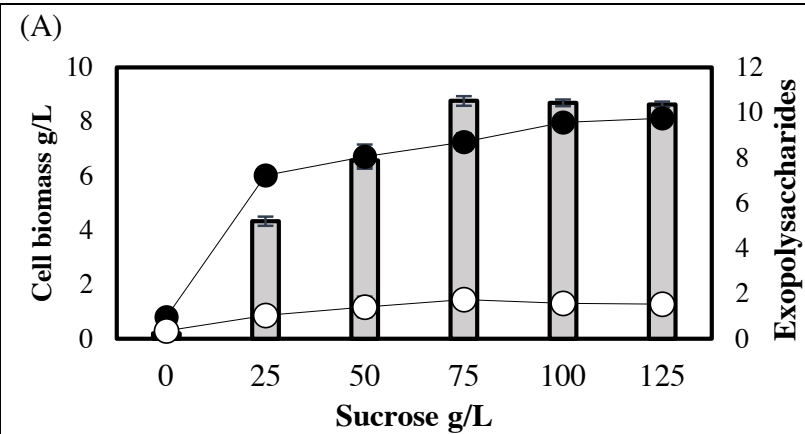

(B)

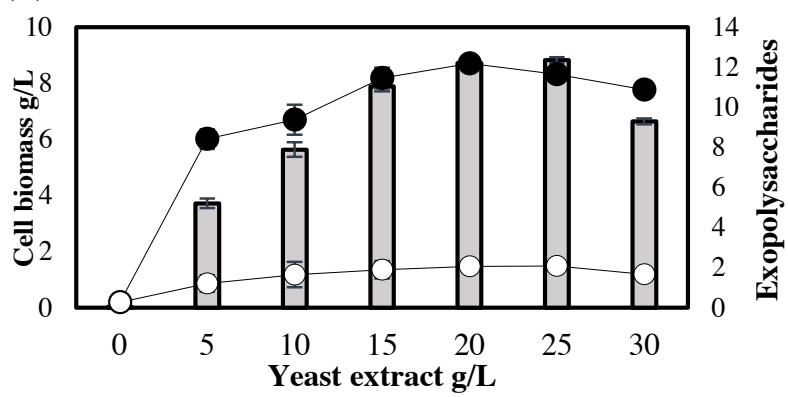

(C)

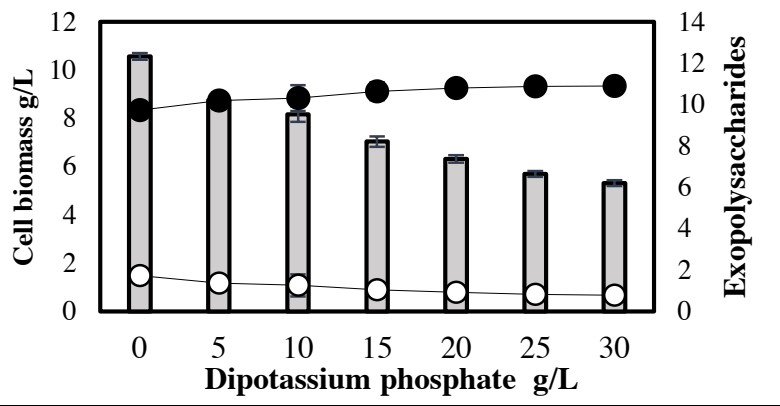

Fig. 1.Effects of sucrose (A), yeast extract (B) and dipotassium phosphate (C) concentration on cell biomass (•), exopolysaccharide (EPS) production (gray bars), and specific production rates ( $($ ) of $B$. zhangzhouensis ZB 16.3.

\section{Conclusion}

Based on the study above, it appears that the enormous diversity and potential of halophiles are not well explored. Most isolated strains are novel species discovered in the last few years and are not much examined for their biotechnological potential to synthesis several bioactive molecules such as exopolysaccharides but also enzymes, proteins, etc.

Production of exopolysaccharides by many potent moderate and extremely halophilic bacteria has been optimized under laboratory conditions and found to produce the polymers in abundant amounts. Such results have resulted in attention for potential applications and exploitation.

In this work, isolated strains proved to be a potential EPSs producer. Further study on optimization will be carried out. According to several studies, other factors influence importantly on EPS production. For many strains, it has been reported that the medium composition, regarding carbon, nitrogen, and mineral sources, plays a crucial role in EPS production.

Acknowledgment. This research is the result of collaborative efforts between the Faculty of Science, Ibn Zohr University, Agadir in Morocco and the Specialized Center of Valorization and Technology of Marine Products, the National Marine Research Institute (CSVTPM - INRH). The authors would like to thank the reviewers for the correction and evaluation of this manuscript.

\section{References}

1. R. Margesin, \& F. Schinner, Biodegradation and bioremediation of hydrocarbons in extreme environments, Appl. Microbiol. Biotechnol. 56(5-6), 650-663 (2001). 
2. I. W. Sutherland, Biofilm exopolysaccharides: a strong and sticky framework, Microbiol., 147(1), 3-9 (2001).

3. R. S. Wotton, The utiquity and many roles of exopolymers (EPS) in aquatic systems, Scientia marina, 68(S1), 13-21 (2004).

4. H. C. Flemming \& J. Wingender, Relevance of microbial extracellular polymeric substances (EPSs)-Part I: Structural and ecological aspects, Water Sci. Technol., 43(6), 1-8 (2001).

5. T. F. Vandamme, A. Lenourry, C. Charrueau \& J. C. Chaumeil, The use of polysaccharides to target drugs to the colon. Carb. Polym., 48(3), 219-231 (2002).

6. A. Pal, \& A. K. Paul, Microbial extracellular polymeric substances: central elements in heavy metal bioremediation. Indian J. Microbiol., 48(1), 49 (2008).

7. P.Verdugo, Marine microgels. Annu. Rev. Mar. Sci. ;4 :375-400 (2012).

8. H.Barsett, A. Ebringerovà, S.E. Harding, T. Heinze, Z. Hromàdkovà, C. Muzzarelli, R.A.A. Muzzarelli, B.S. Paulsen, S.A. El Seoud. In: Polysacch. I. Structure, Characterisation and Use. T. Heinze, editor. Springer; Berlin, Germany (2005).

9. J. Mishra. Microbial Exopolysaccharides In: E. Rosenberg, The Prokaryotes Appl. Bacteriol. Biotechnol. (2013).

10. A. P. Laws \& V. M. Marshall, The relevance of exopolysaccharides to the rheological properties in milk fermented with ropy strains of lactic acid bacteria. Int. Dairy J., 11(9), 709-721 (2001).

11. Y. R. Song, N. E. Song, J. H. Kim, Y. C. Nho, S. H. Baik, Exopolysaccharide produced by Bacillus licheniformis strains isolated from kimchi. J. Gen. Appl. Microbiol., 57: 169-175 (2011).

12. W. G. Weisburg, S. M. Barns, D. A. Pelletier \& D. J. Lane. $16 S$ ribosomal DNA amplification for phylogenetic study. J. Bacteriol., 173(2), 697-703 (1991).

13. A. Klindworth, Evaluation of general 165 ribosomal RNA gene PCR primers for classical and nextgeneration sequencing-based diversity studies, Nucleic Acids Res., vol. 41, no. 1, p. e1, (2013).

14. T. Glockner, De BLAST Sequence Analysis Tool, National Center for Biotechnology Information (US), Bethesda, MA, USA, (2013).

15. S. Kumar, G. Stecher, and K. Tamura, MEGA7: molecular evolutionary genetics analysis version 7.0 for bigger datasets, Mol. Biol. Evol., vol. 33, no. 7, pp. 1870-1874 (2016).

16. N. K. Kılıç \& G. Dönmez, Environmental conditions affecting exopolysaccharide production by Pseudomonas aeruginosa, Micrococcus sp., and Ochrobactrum sp., J. Hazard. Mater., 154(1-3), 10191024 (2008).

17. M. Dubois, K. A. Gilles, J. K. Hamilton, P. T. Rebers $\&$ F. Smith, Colorimetric method for determination of sugars and related substances, Anal. Chem., 28(3), 350-356 (1956).

18. Y. Fan, X. He, S. Zhou, A. Luo, T. He \& Z. Chun, Composition analysis and antioxidant activity of polysaccharide from Dendrobium denneanum. Int. J. Biol. Macromol., 45.2 169-173 (2009).

19. F. Xiong, X. Li, L. Zheng, N. Hu, M. Cui \& H. Li, Characterization and antioxidant activities of polysaccharides from Passiflora edulis Sims peel under different degradation methods, Carbohyd. Polym., 218, 46-52 (2019).

20. H. P. Gandhi, R. M. Ray, R. M. Patel, Exopolymer production by Bacillus species, Carbohyd. Polym. 34: 323-327 (1997).

21. S. Shivakumar \& SVN. Vijayendra, Production of exopolysaccharides by Agrobacterium sp. CFR-24 using coconut water - A byproduct of food industry, Lett. Appl. Microbiol. 42: 477-482 (2006).

22. A. Morin, Screening of polysaccharide-producing microorganisms, factors influencing the production and recovery of microbial polysaccharides, Polysaccharides-Structural Diversity and Functional Versatility. Dumitriu, S.(Ed.), Marcel Dekker Inc. Publication, New York, 275-296 (1998).

23. SVN. Vijayendra \& R. S. Sharath Babu, Optimization of a new heteropolysaccharide production by a native isolate of Leuconostoc sp. CFR-2181, Lett. Appl. Microbiol. 46: 643-648 (2008).

24. A. Groisillier, A. Labourel, G. Michel \& T. Tonon, The mannitol utilization system of the marine bacterium Zobellia galactanivorans, Appl. Environ. Microbiol., 81(5), 1799-1812 (2015).

25. V. Bejar, C. Calvo, J. Moliz, F. Diaz-Martinez \& E. Quesada, Effect of growth conditions on the rheological properties and chemical composition of Volcaniella eurihalina exopolysaccharide, Appl. Biochem. Biotechnol., 59(1), 77-86 (1996).

26. J. S. Smith., A. J. Hillier, G. J. Lees \& G. R. Jago, The nature of the stimulation of the growth of Streptococcus lactis by yeast extract, J. Dairy Res., 42(1), 123-138 (1975).

27. M. A. Jackson, J. S. Frymier, B. J. Wilkinson, P. Zorner \& S. Evans, Growth requirements for production of stable cells of the bioherbicidal bacterium Xanthomonas campestris, J. Ind. Microbiol. Biotech., 21(4-5), 237-241 (1998).

28. H. J. Peppler, 10. Yeast extracts, Econ. Microbiol. (1982).

29. I. W. Sutherland, Biotechnology of microbial exopolysaccharides, Cambridge: Cambridge University Press (1990).

30. K. P. Patil, B. L. Chaudhari \& S. B. Chincholkar. Screening for pharmaceutically important exopolysaccharide producing Streptococci and partial optimization for EPS production, Curr. Trends Biotechnol. Pharm. 3: 329-340 (2009).

31. H. Zhan, C. C. Lee \& J. A. Leigh, Induction of the second exopolysaccharide (EPSb) in Rhizobium meliloti SU47 by low phosphate concentrations, J. Bacteriol. 173: $7391-7394$ (1991). 